\title{
Modelling and Simulation of an Asynchronous Wind Turbine of Squirrel Cage
}

\author{
J. Martínez García, M. García-Gracia, M.P. Comech, D. García García \\ CIRCE-Department of Electric Engineering of the Zaragoza University \\ María de Luna St, 3, 50018 Zaragoza (Spain) \\ Email: mggracia@posta.unizar.es
}

\begin{abstract}
In this paper, a fixed pitch wind turbine equipped with a squirrel cage induction generator is modelled. A detailed model of the static starter is presented. The reactive compensation is achieved by means of three shunt-connected capacitor banks .

In order to be able to make the simulations, also a wind model has been developed. Several wind functions and experimental wind data are allowed by the model.

The results obtained by means of simulation have been contrasted with real results for the validation of the model.
\end{abstract}

\section{Key words}

Squirrel cage generator, static starter, dynamic simulation wind turbine.

\section{Introduction}

Nowadays, the increasing number of wind farms makes necessary the development of suitable tools for investigation of its effects on power quality [1]

This paper is focused to analyze the disturbances produced by an asynchronous wind turbine of fixed pitch.

The presented model is made up of the following elements: the generator, the banks of reactive compensating, the breaker to connect to the grid, the static starter of thyristors and finally the middle voltage transformer of connection to the grid (figure 1).

A squirrel cage wind turbine model is presented in this paper. The model has been developed in PSCAD [2]. The results obtained are in qualitative agreement with experimental values.

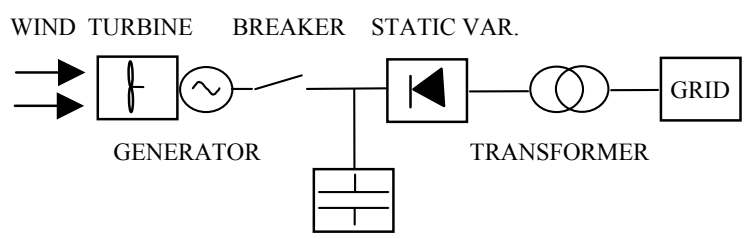

REACTIVE COMPENSATOR

Figure 1. Elements of the wind farm.

\section{Wind turbine model}

The components of the model are described below.

\section{A. Wind model}

A general wind model has been implemented. Ramp, triangular, stair function and random noise can be considered to model the gust. Furthermore, experimental wind data are also accepted in the wind model.

\section{B. Generator model}

The model carried out can be adapted to any squirrel cage wind turbine by varying power, voltage and rated speed.

The simulations of this paper match to a commercial wind turbine of squirrel cage of $600 \mathrm{~kW}$.

The mechanical power of the wind turbine is given [3] by:

$$
P_{M}=1 / 2 \cdot \rho_{A I R} \cdot C_{P} \cdot A_{R} \cdot V^{3}
$$

where $A_{R}$ denotes the swept area of the wind turbine rotor $A_{R}=\pi \cdot R^{2}, \mathrm{R}$ is the blade length, $\mathrm{V}$ is the wind velocity, $\rho_{\text {AIR }}$ is the air density and $C_{p}$ is the power coefficient of the turbine, which is highly dependent on the constructive characteristics.

Applying the relation for the tip-speed ratio $\lambda$ :

$$
\lambda=\frac{w_{M} \cdot R}{V}
$$

where $w_{M}$ is the rotational speed. The mechanical power can be re-written as:

$$
P_{M}=1 / 2 \cdot \rho_{A I R} \cdot \pi \cdot R^{5} \cdot \frac{C_{P}}{\lambda^{3}} \cdot w_{M}^{3}
$$

A soft static starter has been modelled. As in the real starter behaviour of a fixed speed wind turbine, when the wind speed reaches the cut-in speed, the model lets the generator speed rise until 1400rpm.

\section{Connexion System model}

To connect the wind turbine to the network two conditions are required: 
- Wind conditions: The wind speed must be greater than the cut-in speed $(3 \mathrm{~m} / \mathrm{s})$ and lower than the cutout speed $(25 \mathrm{~m} / \mathrm{s})$

\section{- $\quad$ Starter switch must be on.}

The turbine can be disconnected by two reasons:

- Controlled user's stopping. First, switched shunts are disconnected, then the turbine brake is applied. Finally, the disconnection from the grid happened when the turbine turns near synchronism speed
- $\quad$ Emergency stopping due to very high wind speed. In this case, the switch turns off when the cut-out speed is reached.

Other protections (over-current or over-voltage) are not included to analyse the dynamic behaviour of the system without interruptions.

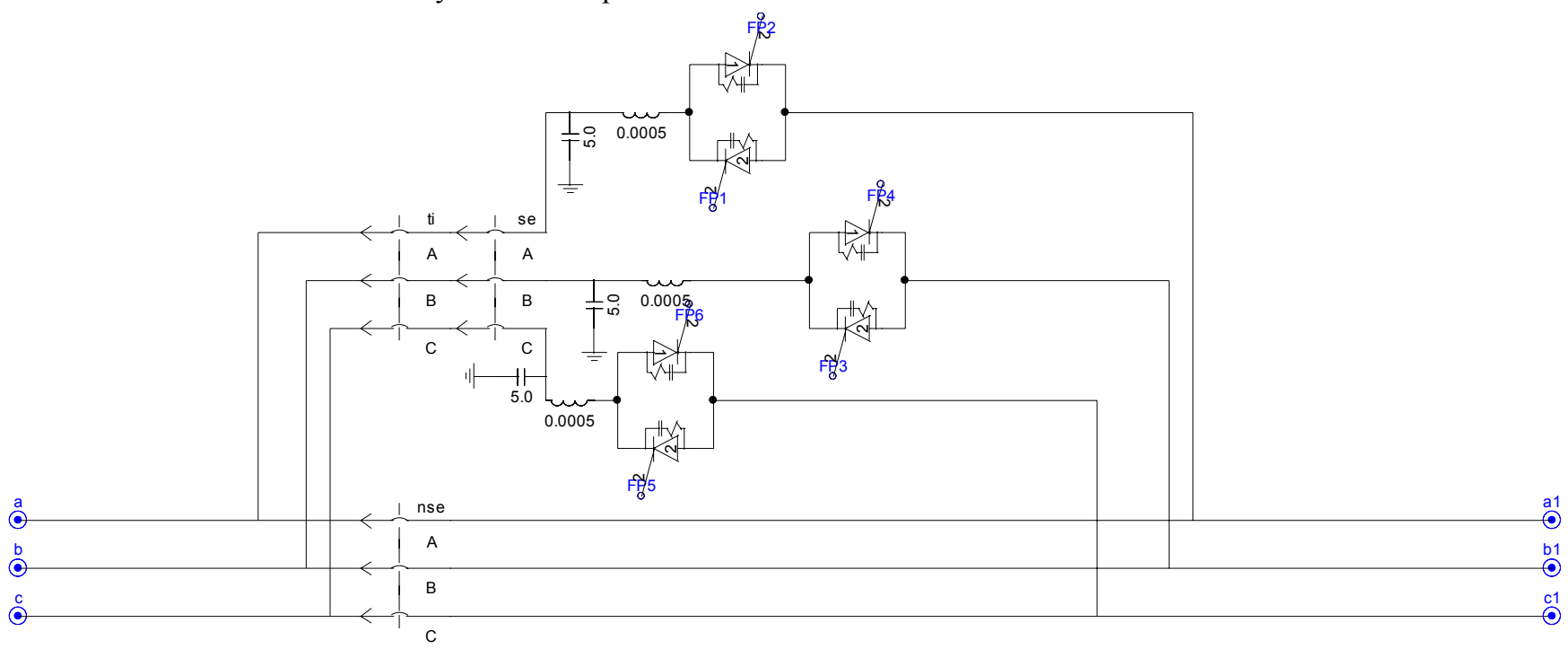

Figure 2. Connexion system model

\section{Static starter model}

When a large wind turbine is switched to the network with a normal switch, a brownout come from the high current required to magnetise the generator. Besides, a power peak is generated due to the current surging into the grid.

Another nasty effect of using a "hard" switch would be to put a lot of extra wear on the gearbox, since the cut-in of the generator would work as if the mechanical brake of the turbine was applied.

To prevent this situation, soft starting $\left[{ }^{4}\right]$ is included in modern wind turbines; it connects and disconnects the turbine gradually to the grid using thyristors. Large power thyristors of wind turbines warm up extremely when they are switched on, so they should be cooled.

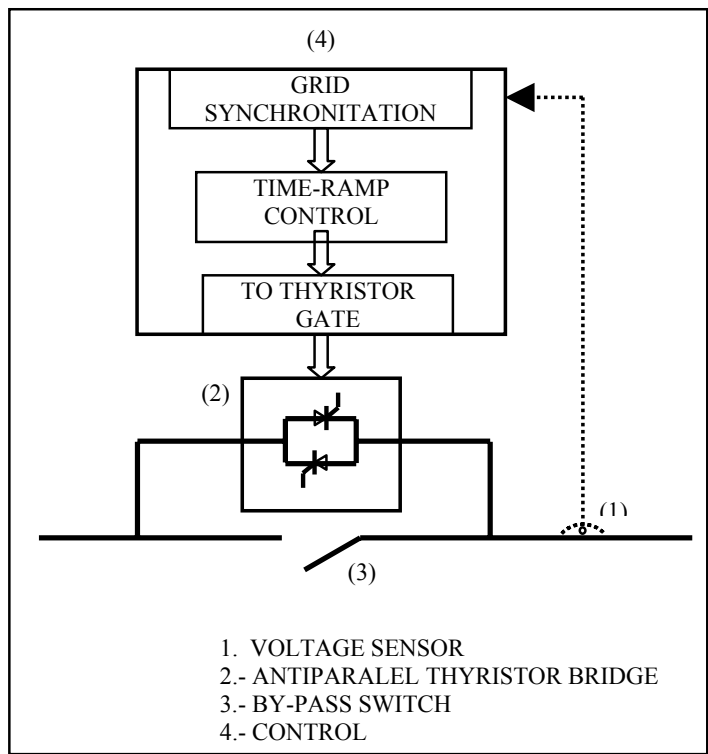

Figure 3. Block diagram of the static starter model.

On other hand, thyristors have a high consumption (about 1 to $2 \%$ of the energy running through them). By this reason, an usual solution consist on bypassing the softstart unit thyristors once the generator has been fully fluxed. Therefore modern wind turbines are normally equipped with a bypass switch (a mechanical switch which is turned on after the turbine has been soft started). 
Then, the energy wasted will be minimised because the energy does not have to pass through the thyristors

In this work, a soft starter has been modelled by means of an anti-parallel thyristor bridge (their disconnection through their bypass switches), so we prevent the sudden grid connection of the wind turbine.

Step synchronization of the trip with the grid frequency is necessary for the right operation of the thyristor bridge. The generator voltage must have the same frequency as received one by the feeder, since we bypassed thyristors and the direct connection between the generator and the network takes place.

The synchronization is carried out by means of a cascade synchronizing transformer or using a programmable hold and sample. In this work, the synchronization is modelled in PSCAD by means of vectorial control. So we obtain a fasor which is turning at the synchronous speed, and with the zero crossings synchronized. This synchronism is fundamental, since the thyristor is a semi-controlled device where the switches off are not controlled.

In the PSCAD model, a pulse with variable wide has been introduced, which works since it has been tripped to the line voltage is zero. So we are sure that the device is driving.

Thyristors are bridged by means of a switch after a specific time period (to prevent losses). This has been developed in PSCAD by means of a ramped set point, which order the trip from $0^{\circ}$ to $180^{\circ}$ (the complete period of wave).

This set point has a working time of one second, it means that it is necessary one second to apply the complete sine wave to the generator.

\section{E. Reactive compensation model}

Dynamic reactive compensation of a wind farm can be structured in several ways. This depends on the factual demands of reactive compensation, controllability of the equipment and the cost.

Depending on the factual demands to reactive power controllability, the compensation units can be organised [5] by:.

1) A continuous reactive power control unit using thyristor-controlled reactors. It is a relatively expensive feature.

2) A discrete control unit with a number of thyristor or mechanically switched capacitors and reactors. It is a relativity cheap feature

3) A combination of discrete and continuous units, where the cost of the feature is optimised knowing the factual demands of the reactive power demands from power stability investigations.
The wind turbine considered is equipped with a static var compensator, which is composed by three shuntconnected capacitors, which supply $150 \mathrm{kVAr}$.

In the reality, the supervision and control microprocessor of the wind turbine connect the compensation battery depending on the generated active power.

\section{F. Transformer and network model}

The wind turbine transformer is a $650 \mathrm{kVA}$ wye-delta transformer $(0,69 / 20 \mathrm{kV})$. The protections and the disconnecting switch have not been modelled to simplify the study.

The network has been modelled by means of a $20 \mathrm{kV}$ generator with infinite inertia.

\section{Results}

The wind turbine starting takes a long time (about 2 minutes).

In this model, several simplifications have considered. The process of acceleration until a speed next to the synchronism one (1430 r.p.m.) is not considered. In the simulations, the wind turbine is directly turning at 1430 r.p.m.. Afterwards, the static starter is connected if the wind speed is greater than the cut-in speed.

Next, a qualitative comparison is made between experimental $\left[{ }^{6}\right]$ and simulation results.

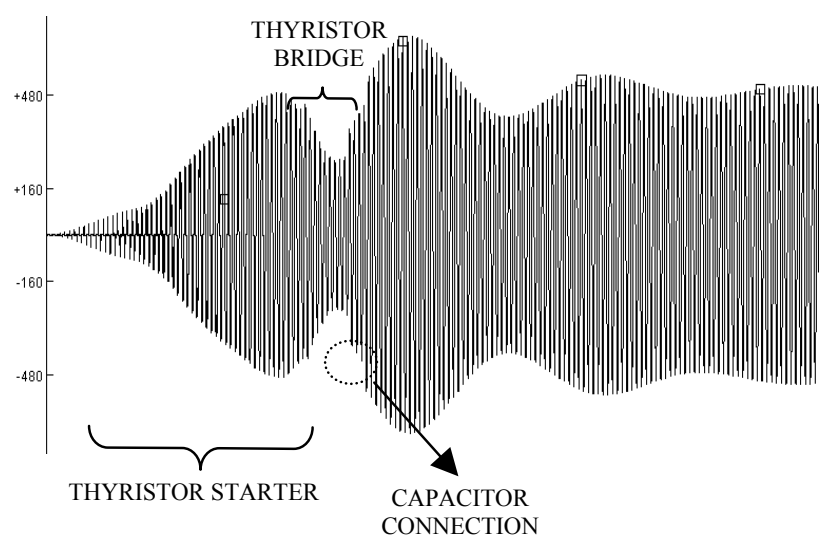

Figure 4. Current for the starting. 


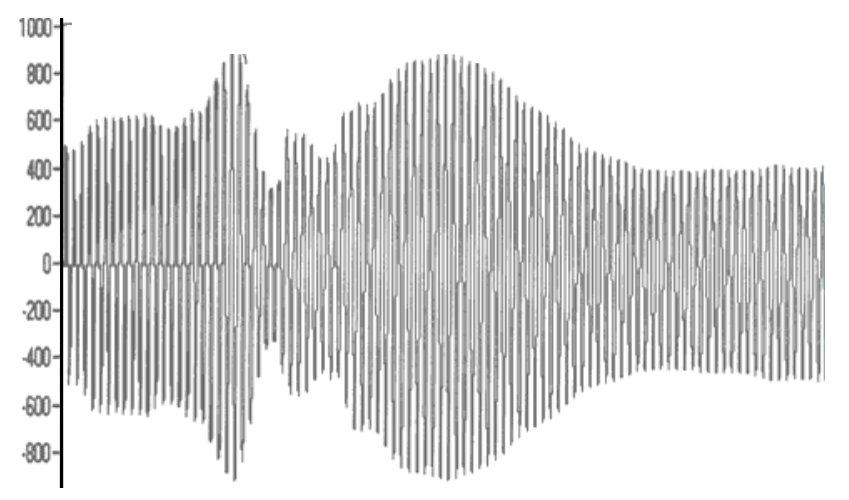

Figure 5. Real current for the starting.

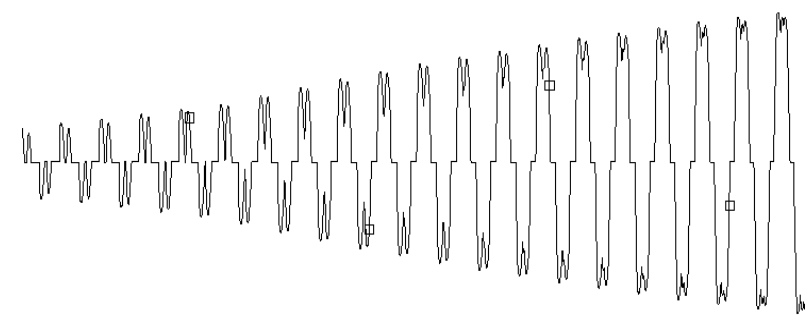

Figure 6. Graphic detail of the current for the starting.

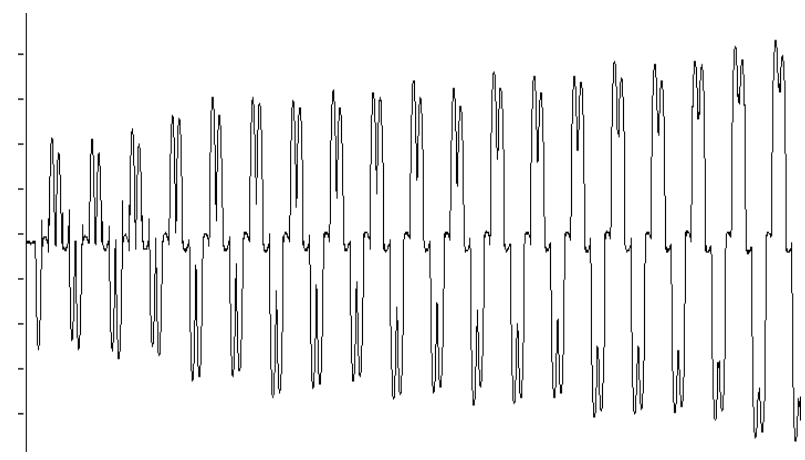

Figure 7. Graphic detail of the real current for the starting.

\section{Conclusion}

A model in PSCAD of a squirrel cage wind turbine of fixed step with sufficient precision has been obtained to study the effects of the disturbances that cause in their operation.

The developed model is valid to any wind turbine based on the squirrel cage technology. Furthermore, it can be used to study the real wind effects, or to obtain the response to voltage sag.

\section{References}

[1] J. M. Rodriguez, J.L. Fernández, D. Beato, R.Iturbe, J. Usaola, P.Ledesma, J. Wilhelmi, "Incidence on Power System Dynamics of High Penetration of Fixed Speed and Doubly Fed Wind Energy Systems: Study of the Spanish Case", IEEE Transactions on Power Systems, Vol 17, No. 4 (2002).

[2] PSCAD / EMTDC V 3.0. Manitoba HVDC Research Centre Inc. $4^{\text {th }}$ edition 2001

[3] A. E. Feijóo, "Influencia de los parques eólicos en la seguridad estacionaria y calidad de onda de redes eléctricas de gran dimensión", $\mathrm{PhD}$ Thesis, University of Vigo.

[4] Cadirci, I.; Ermis, M.; Nalcacl, E.; Ertan, B.; Rahman, M. "A solid state direct on line starter for medium voltage induction motors with minimized current and torque pulsations”. Energy Conversion, IEEE Transactions on , Volume: 14 Issue: 3 , Sept. 1999.

[5] Vladislav Akhmatov. "Analysis of Dynamic Behaviour of Electric Power System with Large Amount of Wind Power", $\mathrm{PhD}$ Thesis, Technical University of Denmark, 2003

[6] J.Mur, S. Ortiz, R. Zapata and D.Romanos. "Análisis de la energía entregada a la red de distribución eléctrica por un parque eólico". University of Zaragoza, 2000. 